\title{
Impacts of urban microclimate on summertime sensible and latent energy demand for cooling in residential buildings of Hong Kong
}

Article

Accepted Version

Creative Commons: Attribution-Noncommercial-No Derivative Works 4.0

Shi, L., Luo, Z., Matthews, W., Wang, Z., Li, Y. and Liu, J. (2019) Impacts of urban microclimate on summertime sensible and latent energy demand for cooling in residential buildings of Hong Kong. Energy, 189. 116208. ISSN 0360-5442 doi: https://doi.org/10.1016/j.energy.2019.116208 Available at https://centaur.reading.ac.uk/86353/

It is advisable to refer to the publisher's version if you intend to cite from the work. See Guidance on citing.

To link to this article DOI: http://dx.doi.org/10.1016/j.energy.2019.116208

Publisher: Elsevier

All outputs in CentAUR are protected by Intellectual Property Rights law, including copyright law. Copyright and IPR is retained by the creators or other copyright holders. Terms and conditions for use of this material are defined in the End User Agreement. 


\section{CentAUR}

Central Archive at the University of Reading

Reading's research outputs online 


\section{Impacts of urban microclimate on summertime sensible and latent energy demand for cooling in residential buildings of Hong Kong}

Luyang Shi ${ }^{1,2,5}$, Zhiwen $\mathrm{Luo}^{2 *}$, Wendy Matthews ${ }^{3}$, Zixuan Wang ${ }^{4}$, Yuguo $\mathrm{Li}^{4}$, Jing $\mathrm{Liu}^{1,5^{*}}$

${ }^{1}$ School of Architecture, Harbin Institute of Technology, Harbin, China

${ }^{2}$ School of Built Environment, University of Reading, Reading, UK

${ }^{3}$ Department of Archaeology, University of Reading, Reading, UK

${ }^{4}$ Department of Mechanical Engineering, The University of Hong Kong, Hong Kong, China

${ }^{5}$ Key Laboratory of Cold Region Urban and Rural Human Settlement Environment Science and Technology, Ministry of Industry and Information Technology, Harbin, China

\section{*Corresponding author:}

Dr. Zhiwen Luo, School of the Built Environment, University of Reading, United Kingdom

Tel: Email: z.luo@ reading.ac.uk

Prof Jing Liu, School of Architecture, Harbin Institute of Technology, China

Tel: Email: liujinghit0@163.com 
Abstract The urban heat island (UHI) and urban moisture island (UMI) effect can be significant in Hong Kong due to its high-density land utilization, and this can strongly affect building energy performance. While the UHI' energy impact has been rather intensively studied recently, the UMI effect on latent energy is still underexplored, especially for humid subtropical climate like Hong Kong. This study investigated the intensity of UHI and UMI in Hong Kong, and its impacts on the sensible and latent cooling demand of residential buildings in summer. Firstly, a ten-year weather dataset from 2004 to 2013 for the six stations selected based on the local climate zone (LCZ) scheme was analysed. The results show that the urban area of Hong Kong appears as both a heat and moisture island during summer nights but as cooling and dry islands during daytime, and the nocturnal UHI and UMI intensity vary significantly with different LCZs. Furthermore, the energy performance of a typical residential building in Hong Kong was simulated with measured weather data for the selected stations as an input. The urban building shows a higher sensible cooling demand, approximately twice that of the comparative rural one, and the latent cooling demand could be up to 96\% higher. Both sensible and latent cooling energy demand decrease with increasing LCZ grades. Our study highlights that both UHI and UMI effect should be considered in the estimation of building energy in Hong Kong due to their significant impacts on the cooling energy demand.

Keywords: urban heat island; urban moisture island; sensible cooling demand; latent cooling demand; residential building 


\section{Introduction}

Globally, the significant increases in populations in urban areas over the recent decades due to rapid urbanization have induced the formation of the local climate change. One of the major factors in this change is the urban heat island (UHI) effect, which describes the excess warmth of the urban atmosphere in comparison to the rural areas [1]. In recent decades, a number of UHI studies have been conducted for the quantification of UHI effect in large cities [2-4]. The magnitude of UHI in different cities mainly depends on anthropogenic heat, building density, the presence of green land and water bodies within the city, and thermal storage in the building fabric [5]. The spatial and temporal variability of the UHI in a city are also very evident [5-6]. It has been shown that UHI effect could result in the increased energy consumption and in summertime heat-related mortality [7].

The impact of UHI on building energy demand have been extensively studied in many large cites using physics-based [8-9] and empirical statistical modelling [10-11]. The UHI studies indicate that the impact of UHI is generally positive for heating load and negative for cooling load [12-14]. Li et al. [15] summarised existing literature and found that the UHI could result in a median increase of $19.0 \%$ in cooling energy consumption and a median decrease of $18.7 \%$ in heating energy. The magnitude of the specific energy impact of UHI effect depends on many factors such as local microclimate, the intensity of urban overheating, and the type and characteristics of buildings [13,15-16]. Toparlar et al. [17] found that cooling demand even of buildings with good thermal insulation and lower infiltration rates, can increase by $48 \%$ once 
moved from the rural location to an urban location of Antwerp, Belgium. Zinzi et al. [18] showed that the UHI caused an increase in cooling consumption up to $74 \%$ for residential building and up to $53 \%$ instead for the office building.

In addition to the UHI effect, local climate change caused by rapid urbanization in large cities is projected to create significant humidity differences between urban and rural areas. Previous studies have shown that urban centres are generally drier than their surroundings, and this phenomenon is termed as urban dry island (UDI) effect [1, 19-21]. As examples, urban absolute humidity was found to be lower than that in rural areas in the Matsuyama Plain by the field measurements and the UDI intensity was significant in daytime [20]. In Milan, the urban area shows lower absolute humidity than rural surroundings for the most time and the interquartile range is between -1.44 $\mathrm{g} / \mathrm{kg}$ and $-0.27 \mathrm{~g} / \mathrm{kg}$, with a median of $-0.67 \mathrm{~g} / \mathrm{kg}[21]$.

However, urban moisture island (UMI) effect, in which the urban humidity level is higher than rural, has been also reported in some other studies [22-24]. Deosthali et al. [22] reported that the core of Pune City appeared as both heat and moisture islands at night but as heat and dry islands at the time of sunrise. Richards [24] found that UMI effect was observed on fine nights in Vancouver by comparing humidity data at urban and rural sites. In summary, UMI effect is normally observed during night-time as the continued evaporation in the city centre during the night is responsible for the excess nocturnal moisture. Several studies have discussed the main causes for the humidity difference between urban and rural areas, but there are only a few quantitative studies on the development for UMI effect. It is acknowledged, however, that evaporation, 
condensation, and anthropogenic moisture emissions contribute to the formation of urban and rural humidity differences [25].

Urban microclimate (UHI and UMI in current study) has a significant impact on building energy performance and could result in positive or a negative feedback on energy demand. While the UHI' energy impact has been quite intensively studied over recent years, the UMI impact on building energy performance is still little researched. To the best of our knowledge, UMI impact on the latent cooling energy has only been investigated as a preliminary case study on climatic conditions in Milan. Simulation results showed the latent cooling load for dehumidification in urban built environment was 74\% 78\% lower than that for rural buildings [21].

Hong Kong, however, has specific features in terms of local climate and urban morphological characteristics in compared to Milan which could result in different UHI and UMI intensities. It is for the reason that the impacts of urban microclimate on the energy performance of buildings in Hong Kong require specific study. Firstly, Hong Kong has a monsoon-influenced humid subtropical climate throughout the year. Summers are very hot and humid, the average air temperature is approximately $28^{\circ} \mathrm{C}$ and the average relative humidity is more than $80 \%$ [26]. Secondly, Hong Kong has unique urban morphological characteristics due to its high-density land utilization with a large population size of around 7.2 million and high urbanization rate [27]. The released anthropogenic heat and moisture therefore is very high in the metropolitan of Hong Kong and could have a significant impact on building energy performance, which really warrants detailed study. 
The aim of this study is to analyse the UHI and UMI effect in Hong Kong and then to quantify their impacts on the energy performance of residential buildings. Most previous studies related to urban microclimate only consider a pair of urban and non-urban stations [28-30]. In this study, we selected six weather stations in Hong Kong based on local climate zone (LCZ) scheme. The spatial characteristics of UHI and UMI effect in different LCZs of Hong Kong are assessed by analysis of the data from a ten-year period of monitoring temperature and relative humidity. Furthermore, the measured weather data for various LCZs are used as input for building energy simulation to evaluate their impacts on energy demand, including sensible and latent cooling demand. As over $90 \%$ of people live in high-rise apartment in Hong Kong [31], we selected a representative high-rise residential building as a case study.

\section{Methodologies}

\subsection{Weather stations of Hong Kong}

In terms of urban microclimate, it is crucial to select the appropriate meteorological sites to be used to quantitatively investigate UHI and UMI effect $[32,33]$. Siu et al. [34] utilized LCZ landscape classification system to classify 17 weather stations of Hong Kong and obtained most representative meteorological sites to calculate heat island intensity. According to Siu's research results [34] and LCZ map of Hong Kong $[26,33]$, we selected six weather stations from meteorological observation network to represent the corresponding LCZs [34]. Table 1 summarises the main LCZ features of the selected stations [34]. The detailed information about LCZs is presented in refs. 
[33-34], including the boundaries of LCZs, land use surrounding weather stations, and other associated urban morphology database. The relative locations of the six stations are presented in Fig.1 as denoted by the red cycles. The variations of the altitude among the selected stations are very small and thus the impacts of topographies of the stations can be neglected in urban climate studies [26, 34].

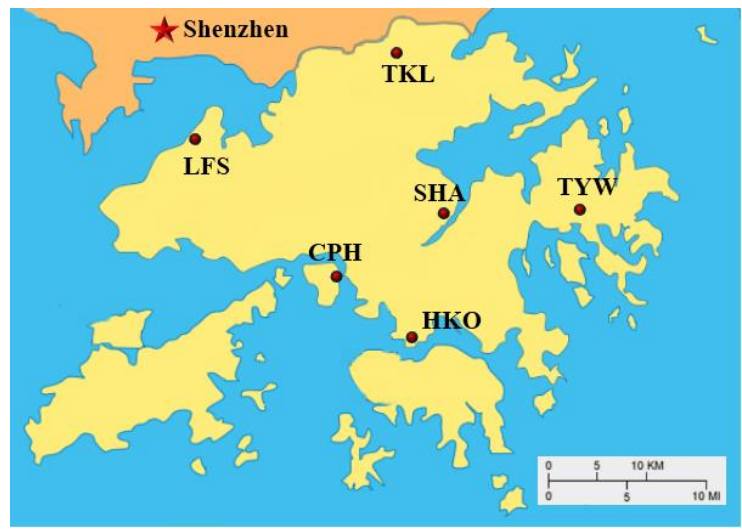

Fig.1 Relative location of the six selected weather stations in Hong Kong as denoted by the red cycles

Specifically, Hong Kong Observatory (HKO) is used as a representative urban site and it is the only site classified as Compact High Rise Zone (BCZ1). Ching Pak House $(\mathrm{CPH})$ station is situated in a public housing estate and is attributed to Open-Set Blocks (BCZ5). Based on the LCZ scheme, Sha Tin (SHA) station and Lau Fau Shan (LFS) station is classified as Extensive Low-Rise (BCZ6) and Lightweight Low-Rise Zone (BCZ8), respectively. Ta Kwu Ling (TKL) station is classified into the Dispersed Low-Rise Zone (BCZ10). Tsak Yue Wu (TYW) is the best choice of representative rural stations in Hong Kong based on current weather station network. Overall, the six stations from urban area to rural area in sequence are $\mathrm{HKO}, \mathrm{CPH}$, SHA, LFS, TKL, and then TYW, and LCZ grades of the stations increase in that order. 
Note that the proportion of building density in the six selected LCZs decreases with increasing LCZ grades and the proportion of green land increases.

Table 1 The Local Climate Zone designation of the selected weather stations in Hong Kong

\begin{tabular}{|c|c|c|c|c|c|}
\hline $\begin{array}{l}\text { Station } \\
\text { name }\end{array}$ & LCZ classifications & $\begin{array}{l}\text { Proportion } \\
\text { built }(\%)\end{array}$ & $\begin{array}{l}\text { Proportion } \\
\text { green }(\%)\end{array}$ & $\begin{array}{l}\text { Proportion } \\
\text { water }(\%)\end{array}$ & $\begin{array}{c}\text { Aerial photograph } \\
\text { of the station }\end{array}$ \\
\hline HKO & $\begin{array}{c}\text { Compact High-Rise } \\
\text { (BCZ1) }\end{array}$ & 80.0 & 20.0 & 0.0 & \\
\hline $\mathrm{CPH}$ & Open-Set Blocks (BCZ5) & 72.2 & 27.5 & 0.3 & \\
\hline SHA & $\begin{array}{c}\text { Extensive Low-Rise } \\
\text { (BCZ6) }\end{array}$ & 57.9 & 25.6 & 16.5 & \\
\hline LFS & $\begin{array}{l}\text { Lightweight Low-Rise } \\
\text { (BCZ8) }\end{array}$ & 42.3 & 30.4 & 27.3 & \\
\hline TKL & $\begin{array}{c}\text { Dispersed Low-Rise } \\
\text { (BCZ10) }\end{array}$ & 18.1 & 81.9 & 0.0 & \\
\hline TYW & Forest (NCZ1) & 2.7 & 96.7 & 0.6 & \\
\hline
\end{tabular}

Note: the data is from the ref. [34]; Aerial photograph of the stations is from Google Earth.

It should be noted that the weather data for all selected LCZs were acquired every one hour for the period 2004-2013, including air temperature, relative humidity, wind direction and wind speed, and solar radiation. 


\subsection{UHI/UMI analysis at local scale}

UHI intensity (UHII) is a well-known quantitative indicator of the UHI effect and it is defined as the air-temperature difference between an urban area and surrounding rural area. In order to quantitatively characterize UHII, some appropriate indices have been proposed in previous studies [5, 15-16]. For example, UHII is quantified using the maximum daily temperature difference between the urban and the reference rural one in some studies [32]. The California EPA developed a new UHI index, which is the cumulative value of UHII over a designated period [5]. Wang et al. [35] used diurnal cycle of UHII calculated by hour air temperature at four weather stations to study UHI effect. In order to obtain the diurnal pattern of local UHI effect in Hong Kong, we calculated the diurnal cycle of UHII during summer using hourly air temperature in this study. The summertime in Hong Kong was considered from $1^{\text {st }}$ May to $31^{\text {th }}$ September [35].

$$
U H I I=T_{\text {urban }}-T_{\text {rural }}
$$

where, $T_{\text {urban }}$ is the hourly air temperature at the urban weather station in ${ }^{\circ} \mathrm{C} ; T_{\text {rural }}$ is the hourly air temperature at the reference rural station in ${ }^{\circ} \mathrm{C}$.

Generally, UMI refers to the condition where higher humidity values are observed in urban area compared with the rural area. In the previous studies, the quantification of the UMI effect is generally computed on the basis of hourly vapour pressure [23-24, 36], and relative humidity [37]. The higher vapour pressure in the urban site than the rural indicates a more humid air in the urban area. In this study, we used absolute humidity to calculate UMI intensity (UMII) for the quantification of UMI magnitude 
in Hong Kong. Similar to UHII, we also calculated the diurnal cycle of UMII during summertime in Hong Kong using hourly absolute humidity in Eq.(2):

$$
U M I I=H_{\text {urban }}-H_{\text {rural }}
$$

where, $H_{\text {urban }}$ is the hourly absolute humidity at the urban weather station in $\mathrm{kg} / \mathrm{kg}$; $H_{\text {rural }}$ is the hourly absolute humidity at the reference station in $\mathrm{kg} / \mathrm{kg}$.

It should be noted that the UMII is negative when the urban dry island (UDI) phenomena take place. The larger the UMII is, the more significant the humidity difference between the urban and rural area could be. In this study, the UHII and UMII for the selected weather stations is calculated considering TYW station as the reference rural site.

\subsection{Building model and simulation settings}

The numerical analysis for building energy demand was performed using the DeST software developed by Tsinghua University, China [38]. DeST software has become a widely-used platform for simulating dynamic building thermal process and energy performance [39] and it has been validated by many studies [40-41]. The State Space method is adopted in DeST to solve the discrete nodes of the energy balance equation sets, and then all response factors for heat disturbances can be obtained [38]. Based on these response factors, the hourly sensible and latent loads could be computed. This method is able to obtain the solution of the equation sets directly without calculating the temperature field and thus save a lot of computing time. Besides, DeST developed a graphical input interface that is based on AutoCAD for all simulation process in 
order to avoid additional modelling work and information loss [38].

As a case study, we selected a typical hypothetic 30-story residential building [42-43], which is widely occupied in Hong Kong [31, 44]. The simulations were carried out for the whole year using the weather datasets collected from governmental observations over ten years (2004- 2013). Fig.2 presents the floor layout of the residential building as the chosen prototype building model in DeST. The components and the thermal performance of building envelopes are detailed in Table 2 [42-43]. Each floor of the building is composed of eight apartments and each apartment is occupied by a four-person family [42]. The residential building is assumed to be occupied from evening to the early morning of the following day (18:00-8:00 am). In the simulation, we assume all windows are closed, and there is only infiltration of 0.5 $\mathrm{h}^{-1}$ [5]. Table 3 gives internal heat gains and moisture sources from the illumination, equipment and individuals [42].

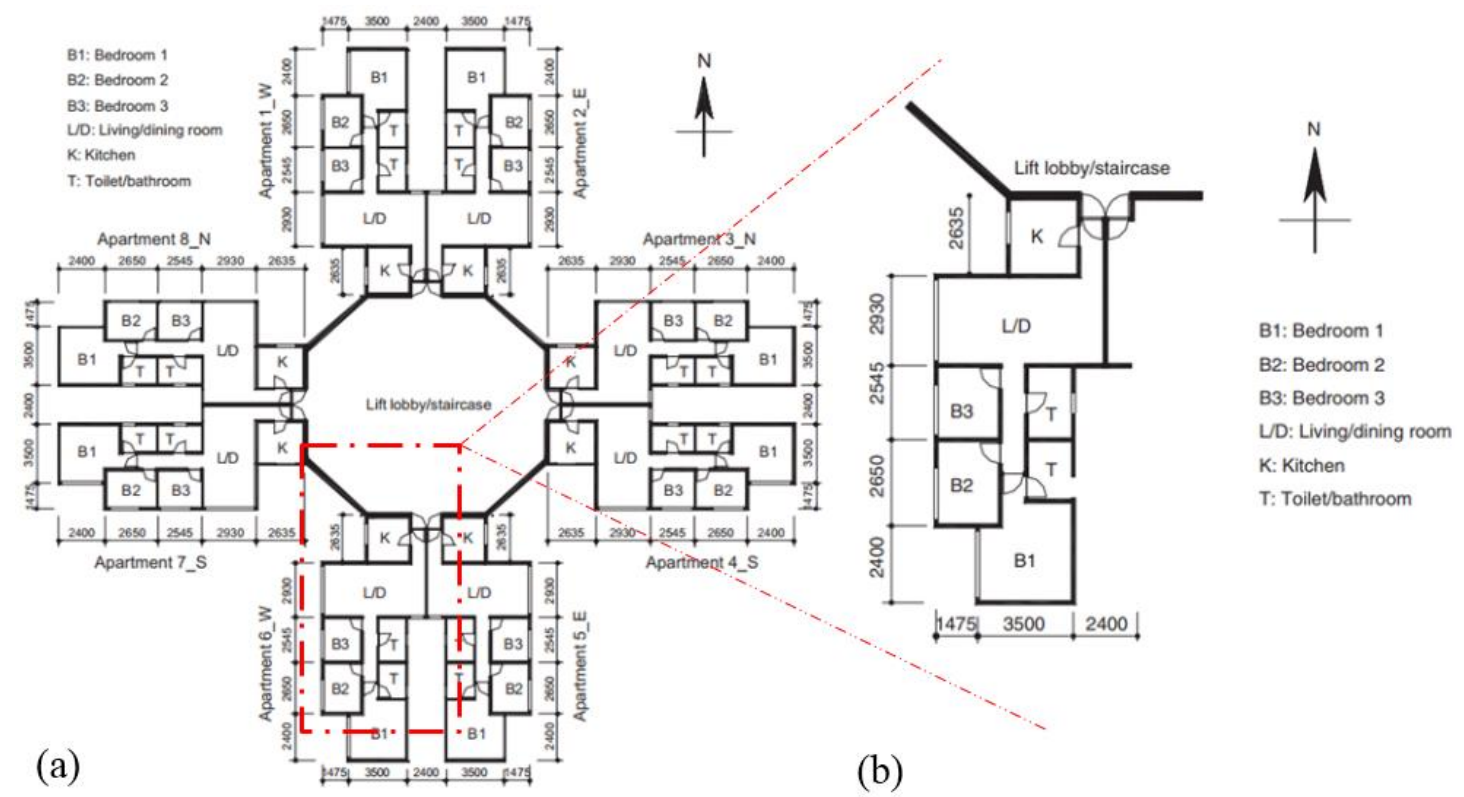

Fig.2 The floor layout of the reference residential building (a) and a west-facing apartment under study

(b) (unit: mm; see ref. [42, 43]) 
In the simulation, the air temperature set-point for the air-conditioning system is set to $26^{\circ} \mathrm{C}$, and the set-point of relative humidity is $60 \%$ during the occupied hours in summer. The air-conditioning system is operated when the residential building is occupied from 18:00-8:00 in the following day and shut down during daytime. The hourly sensible and latent cooling load of the residential building is then calculated based on the above simulative settings using DeST.

Table 2 Components and the thermal performance of the building envelope

\begin{tabular}{lll}
\hline $\begin{array}{l}\text { Building } \\
\text { element }\end{array}$ & Building envelope components & $\begin{array}{l}\text { U-value } \\
\left(\mathrm{W} / \mathrm{m}^{2} \cdot \mathrm{K}\right)\end{array}$ \\
\hline External walls & $13 \mathrm{~mm}$ Cement/sand plaster $+100 \mathrm{~mm}$ concrete $+13 \mathrm{~mm}$ gypsum plaster & 2.4 \\
Flooring & $5 \mathrm{~mm}$ Vinyl tiles $+25 \mathrm{~mm}$ Cement $/$ sand screed $+100 \mathrm{~mm}$ concrete & 2.2 \\
Window & $5 \mathrm{~mm}$ glass + a generic interior window shade + an external attached & 3.45 \\
& shading concrete slab of $500 \mathrm{~mm}$ width & \\
\hline
\end{tabular}

Note: the thermal physical properties of building materials are detailed in refs. [42, 43]

Table 3 Internal heat gains and moisture sources from the illumination, equipment and individuals

\begin{tabular}{llllll}
\hline Schedule & $\begin{array}{l}\text { Presence of } \\
\text { people }\end{array}$ & $\begin{array}{l}\text { Illumination } \\
\left(\mathrm{W} / \mathrm{m}^{2}\right)\end{array}$ & $\begin{array}{l}\text { Equipment } \\
\left(\mathrm{W} / \mathrm{m}^{2}\right)\end{array}$ & $\begin{array}{l}\text { Occupants } \\
\text { Heat loads }(\mathrm{W} / \mathrm{p})\end{array}$ & Moisture loads $(\mathrm{g} / \mathrm{p})$ \\
\hline 7:00-8:00 & Present & 8 & 24 & 66 & 60 \\
8:00-18:00 & No present & 0 & 1 & 0 & 0 \\
18:00-22:00 & Present & 16 & 24 & 66 & 60 \\
22:00-7:00 & Present & 0 & 1 & 40 & 50 \\
\hline
\end{tabular}

Note: the activity levels of occupants are assumed to be $66 \mathrm{~W} / \mathrm{p}$ for heat and $90 \mathrm{~g} / \mathrm{p}$ for moisture when they are awake; $40 \mathrm{~W} / \mathrm{p}$ and $50 \mathrm{~g} / \mathrm{p}$ when they sleep.

To estimate electricity demand, we assume that the reference building is equipped with window-type room air-conditioners (RACs) and the coefficient of performance (COP) of the RAC units for residential air conditioning is 2.63 in Hong Kong [45]. 
The amount of electricity demand $E(W)$ can be calculated based on the simulated results of DeST using following equation [46]:

$$
E=\left(E_{s}+E_{l}\right) / C O P
$$

where, $E_{S}$ is the calculated energy demand for sensible cooling in $\mathrm{kWh} ; E_{l}$ is the calculated energy demand for latent cooling in kWh.

\section{Results and discussions}

\subsection{Urban microclimate analysis}

The focus of this section is the results for summertime UHI and UMI with the comparisons among different LCZs, providing a better understanding of temporal and spatial characteristics of UHI and UMI effect in Hong Kong. The average diurnal cycles of hourly urban temperature and absolute humidity in summer are calculated by using ten-year average meteorological data (2004-2013). It should be noted that the diurnal cycle is a ten-year average day in the summer period instead of a selected particular day and year from ten-year data.

\subsubsection{Urban heat island (UHI)}

Results for the daily course of hourly air temperature and UHII at the six selected weather stations in Hong Kong during summer are shown in Fig.3. The derived UHII in a day shows U-shaped diurnal variations, with high values at nighttime and low values during the daytime. Summertime UHI in Hong Kong is at its lowest intensity from early morning to nightfall, and then it starts increasing rapidly and reaches its 
maximum intensity during the night. This indicates that UHI effect in Hong Kong is more intense at night and less pronounced during the daytime and this trend is similar to the previous UHI studies [5-6, 47].
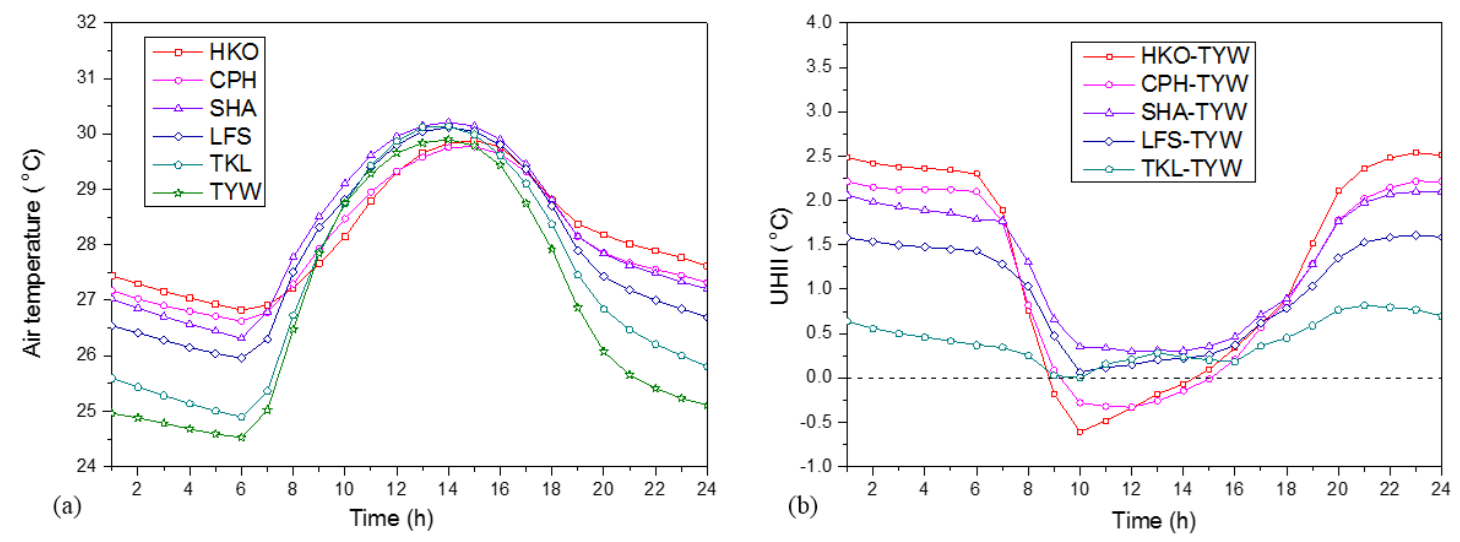

Fig.3 Diurnal variations for air temperature at the six weather stations of Hong Kong during summer over ten years (a), and diurnal cycle of UHII calculated considering TYW as the rural reference site (b); the local standard time (LST) is used in the graphs

In the diurnal cycle, UHII for all the stations are positive during the night, but could be negative during daytime between 9:00 and 15:00 LST in HKO and CPH. This indicates that these two urban areas exhibit urban cool island (UCI) over the period. The cooler urban daytime can be observed only in high-rise compact LCZs, but not in the low-rise zones. Therefore, the daytime UCI phenomenon during summer may be caused by the combined effects of high-compact urban morphology [48] and canyon shading around the urban site [49].

As shown in Fig.3 (b), the trend for diurnal variations of UHII for the six stations is almost identical, but differs in magnitude. Table 4 summarises the average UHII and maximum daily UHII for five stations during summer over ten years using TYW as the reference rural station. The daytime in summer is calculated for 8:00 to 20:00 LST and night time is from 21:00 to 7:00 LST of the next morning. 
Significant differences are observed in the five stations depending on the urban LCZs. During summer, HKO has the highest nocturnal UHII, with an average UHII of $2.4^{\circ} \mathrm{C}$, followed by $\mathrm{CPH}$ with a very small gap $\left(2.1^{\circ} \mathrm{C}\right)$. This is mainly due to the impact of anthropogenic heat which is an important component of the local energy balance in the centre of city. The two suburban weather stations fall in the middle, with the UHII of $1.9^{\circ} \mathrm{C}$ and $1.5^{\circ} \mathrm{C}$ for SHA and LFS, respectively. The UHII for TKL is the lowest, only $0.6^{\circ} \mathrm{C}$, indicating a small temperature difference between TKL and TYW. The greatest difference of average UHII among LCZs reaches $1.8^{\circ} \mathrm{C}$ during summer night. It is worth noticing that the nocturnal UHII decreases in proper order from urban to rural area based on the LCZ classification.

Table 4 Nocturnal and diurnal UHII for various stations over the ten years in summer

\begin{tabular}{lllllll}
\hline \multirow{2}{*}{ Time } & \multicolumn{5}{l}{ Summertime UHII $\left({ }^{\circ} \mathrm{C}\right)$} & \\
\cline { 3 - 6 } & & HKO & CPH & SHA & LFS & TKL \\
\hline Daytime & Average + SD & $0.2 \pm 0.61$ & $0.3 \pm 0.52$ & $0.7 \pm 0.36$ & $0.5 \pm 0.33$ & $0.3 \pm 0.15$ \\
8:00-18:00 & Maximum & $2.1 \pm 0.91$ & $1.8 \pm 0.76$ & $1.7 \pm 0.80$ & $1.4 \pm 0.42$ & $0.7 \pm 0.39$ \\
Night & Average + SD & $2.4 \pm 0.16$ & $2.1 \pm 0.12$ & $1.9 \pm 0.11$ & $1.5 \pm 0.09$ & $0.6 \pm 0.15$ \\
19:00-7:00 & Maximum & $2.6 \pm 0.34$ & $2.2 \pm 0.28$ & $2.1 \pm 0.31$ & $1.6 \pm 0.11$ & $0.8 \pm 0.24$ \\
\hline
\end{tabular}

Note: ten years refer to 2004-2013; SD refers to standard deviations among ten years.

However, the average UHII for various LCZs during daytime show completely different trend. The daytime UHII for SHA and LFS are $0.7^{\circ} \mathrm{C}$ and $0.5^{\circ} \mathrm{C}$, respectively. The median UHII for $\mathrm{HKO}$ and $\mathrm{CPH}$ are both very low, in the range of $0.2^{\circ} \mathrm{C} \sim 0.3^{\circ} \mathrm{C}$, and these are almost the same with TKL. This could be attributed to the presence of UCI phenomenon during the daytime in $\mathrm{HKO}$ and $\mathrm{CPH}$. Overall, the correlation between the daytime UHII with the grades of LCZs is relatively low possibly due to many complicated factors during daytime, such as UCI effect, solar radiation, 
atmospheric moisture levels, etc.

\subsubsection{Urban moisture island (UMI)}

The daily course of the absolute humidity at six weather stations during summer is presented in Fig.4. The absolute humidity in the urban area is higher than its rural surroundings at night but lower during the daytime. The diurnal variation with larger urban moisture excess is observed at night, then rapidly reduces following sunrise and increases after sunset significantly. As shown in Fig.4 (b), the nocturnal UMII is positive while the diurnal UMII is negative, showing a dry island in the daytime and moisture island at nighttime. Indeed, the elevated air temperatures due to high nocturnal UHII cause continued evaporation and reduced condensation in the city centre, which leads to the moisture excess in urban area. During daytime, absolute humidity for the rural sites significantly increases due to the enhanced effect of the evaporation and the transpiration after sunrise and it causes daytime UDI effect.
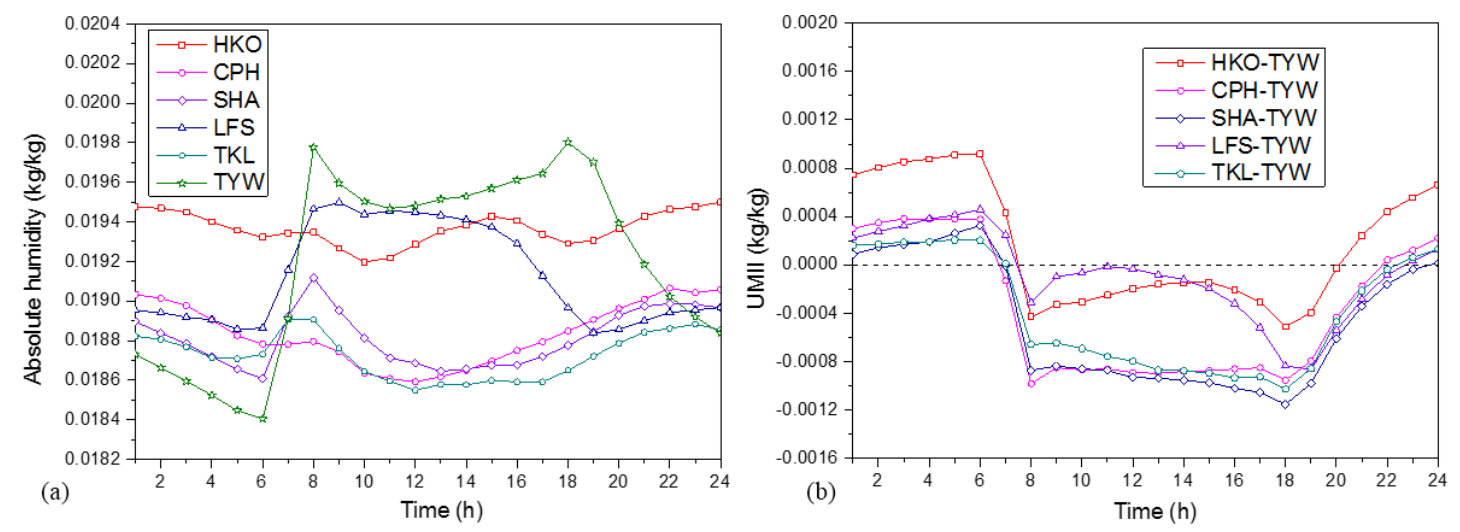

Fig.4 Diurnal cycle for absolute humidity at six weather stations of Hong Kong in summer over ten

years (a), and diurnal cycle of UMII calculated considering TYW as the rural reference site (b); the

local standard time (LST) is used in the graphs 
Note that the increments in absolute humidity after sunrise for the all selected LCZs vary in magnitude except for $\mathrm{HKO}$ and $\mathrm{CPH}$. Specifically, the largest increment in absolute humidity is for TYW, possibly due to stronger transpiration of the plants (the proportion of green is $96.6 \%$ in TYW). LFS takes the second place rather than TKL although TKL has higher LCZ grades. Surrounding water body possibly contributes to the formation of the absolute humidity difference, and the proportion of water body in LFS is the largest among the six stations, up to $27.3 \%$. Conversely, the variations of the daily absolute humidity for two urban areas are very low, a maximum of $0.3 \mathrm{~g} / \mathrm{kg}$ for $\mathrm{HKO}$ and $0.47 \mathrm{~g} / \mathrm{kg}$ for $\mathrm{CPH}$.

In order quantitatively to compare UMII in different LCZs, we summarised the average UMII and maximum daily UMII over ten years, as shown in Table 5. At night, HKO is the most humid station, and the average UMII in HKO is up to $0.68 \mathrm{~g} / \mathrm{kg}$. The nocturnal UMII in TKL is the lowest, with an average of $0.10 \mathrm{~g} / \mathrm{kg}$. For CPH, SHA, and LFS, the nocturnal UMII is $0.20 \mathrm{~g} / \mathrm{kg}, 0.16 \mathrm{~g} / \mathrm{kg}$ and $0.19 \mathrm{~g} / \mathrm{kg}$, respectively. In summer, the nocturnal UMII decreases with increasing LCZ grades according to local urban climate except for LFS. Higher UMII in LFS than SHA is clearly observed during the night, and this is probably affected by the proportion of water body, which is the largest in LFS.

During daytime, UDI phenomenon appears at all selected stations and UMII differ based on LCZ classifications. UDI effect in SHA is more pronounced than other LCZs, and UDI intensity reaches $0.93 \mathrm{~g} / \mathrm{kg}$. CPH is the second largest UDI intensity, with an average of $0.85 \mathrm{~g} / \mathrm{kg}$. It should be noted that UDI intensity in the core of the 
Hong Kong (HKO) is relatively small during daytime, only $0.26 \mathrm{~g} / \mathrm{kg}$, and this is due to significant anthropogenic emissions of moisture from human activity in city centre. Actually, the UDI effect during the daytime is more complicated than that during the night, and there is no obvious relationship between UDI intensity and LCZ grades. Generally, the urban area is drier than the rural one, but the centre of city is not the driest due to the excess of anthropogenic moisture.

Table 5 Nocturnal and diurnal UMII for various stations over the ten years in summer

\begin{tabular}{lllllll}
\hline \multirow{2}{*}{ Time } & \multicolumn{2}{l}{ Summertime UMII $(\mathrm{g} / \mathrm{kg})$} & & \\
\cline { 3 - 7 } & & HKO & CPH & SHA & LFS & TKL \\
\hline Daytime & Average + SD & $-0.26 \pm 0.06$ & $-0.85 \pm 0.21$ & $-0.93 \pm 0.23$ & $-0.30 \pm 0.08$ & $-0.79 \pm 0.19$ \\
8:00-18:00 & Minimum & $-0.51 \pm 0.12$ & $-0.98 \pm 0.47$ & $-1.15 \pm 0.53$ & $-0.86 \pm 0.37$ & $-1.02 \pm 0.50$ \\
Night & Average + SD & $0.68 \pm 0.23$ & $0.20 \pm 0.18$ & $0.16 \pm 0.12$ & $0.19 \pm 0.11$ & $0.10 \pm 0.08$ \\
19:00-7:00 & Maximum & $0.92 \pm 0.31$ & $0.40 \pm 0.25$ & $0.32 \pm 0.19$ & $0.45 \pm 0.12$ & $0.21 \pm 0.10$ \\
\hline
\end{tabular}

Note: ten years refer to 2004-2013; SD refers to standard deviations among ten years.

\subsection{Building energy performance}

This section is dedicated to investigating the impacts of the UHI and UMI effect on the energy demand of the residential building in Hong Kong. DeST simulations give the hourly resulting data, including hourly sensible and latent cooling load. Based on these simulative results, we calculated the accumulated sensible and latent demand for cooling on summertime as the evaluation index. Finally, we combined the two parts of energy demand for cooling to estimate electricity demand during summer.

\subsubsection{Impact on the sensible cooling demand}

The variations of the sensible cooling demand for the six LCZs over ten years are 
presented in Fig.5. A large inter-annual variability from 2004 to 2013 is observed and this should be attributed to different climatic conditions among the monitoring years. For instance, the maximum variation in HKO is between 2004 and 2009, up to 25.23 $\mathrm{kWh} / \mathrm{m}^{2} \mathrm{y}$. Focusing on the inter-annual variability, the range is $24 \%-33 \%$ of sensible cooling demand in urban building, while it is of $36 \%-37 \%$ for the rural case. This indicates that the highly dense and compact urban conditions seem to buffer the inter-annual variability of sensible energy demand for cooling. Additionally, one interesting observation is that the highest sensible cooling loads for all selected LCZs occurred in 2009 corresponding to the highest air temperature in that year.

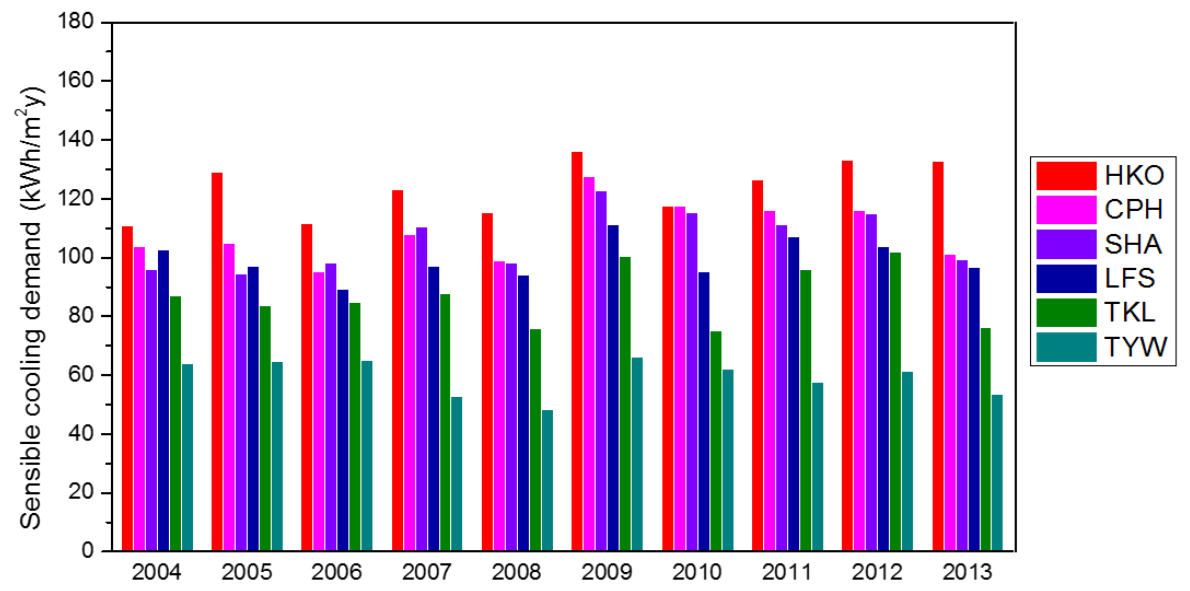

Fig.5 Simulated results for sensible cooling demand of the reference residential building over ten years (2004 2013) in different LCZs of Hong Kong

While the inter-annual variations are clearly observed in Fig.5, the urban scenario always shows higher sensible cooling energy compared to the rural scenario over ten years. The maximum difference between $\mathrm{HKO}$ and reference rural site is equal to 79.34 $\mathrm{kWh} / \mathrm{m}^{2} \mathrm{y}$ in 2013. As expected, the UHI effect leads to an increase of the sensible cooling demand in the urban environment, but the energy performance of the residential building follows different path according to urban climate characteristics. 
For simplicity, Fig.6 (a) summarises ten-year average of sensible cooling demand for all selected LCZs. Besides, Fig.6 (b) also shows the correlations between the relative variation of sensible cooling demand and UHII during summer night.

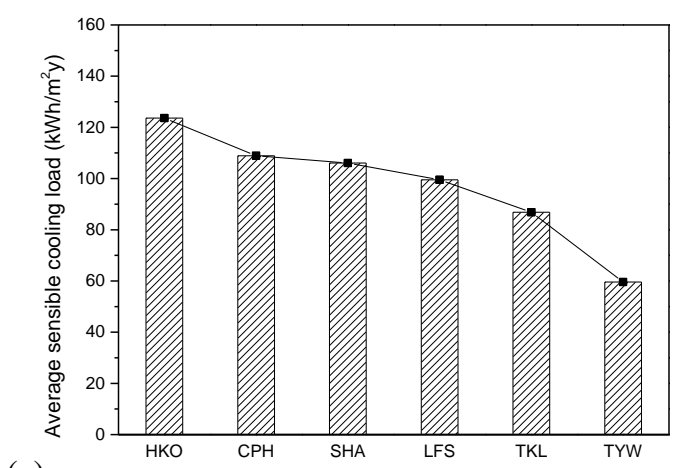

(a) (b)

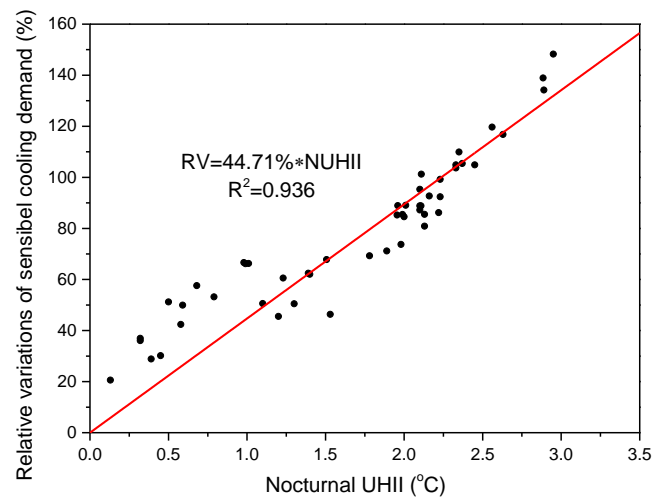

Fig.6 Average sensible cooling demand of all LCZs over ten years during summer (a) and the correlations between the relative variation (RV) of sensible cooling demand and nocturnal UHII (b)

Overall, the sensible cooling demand decreases uniformly from the urban to rural areas according to LCZ classification. The sensible cooling demand is the largest in $\mathrm{HKO}$, an average of $123.64 \mathrm{kWh} / \mathrm{m}^{2} \mathrm{y}$, which decreases significantly in the rural cases, $86.83 \mathrm{kWh} / \mathrm{m}^{2} \mathrm{y}$ in TKL and $59.58 \mathrm{kWh} / \mathrm{m}^{2} \mathrm{y}$ in TYW, respectively. CPH and two semi-urban zones (SHA and LFS) fall in the middle, and there is only a slight difference among them, in the range of $99.45 \sim 108.90 \mathrm{kWh} / \mathrm{m}^{2} \mathrm{y}$. To be noted, the sensible cooling demand for the urban building in $\mathrm{HKO}$ is more than twice of the rural building. Compared to TYW, the relative difference of sensible cooling demand is $82.8 \%, 78.0 \%, 67.0 \%$, and $45.7 \%$ for $\mathrm{CPH}$, SHA, LFS, and TKL, respectively.

In fact, the discrepancy for various LCZs is associated with nocturnal UHII during summer with respect to the residential building. The correlation factor is 0.936 , as shown in Fig.6 (b). This high value indicates that an increase of $1.0^{\circ} \mathrm{C}$ in nocturnal 
UHI intensity during summer results in a $44.71 \%$ increase in the relative difference of the sensible cooling demand for urban residential building in Hong Kong.

\subsubsection{Impact on the latent cooling demand}

Fig.7 shows the latent cooling demand for dehumidification for residential building in different LCZs in Hong Kong from 2004 to 2013. On the whole, the latent cooling demand approximately accounts for 35\% 52\% of sensible cooling demand, and this is a considerable proportion. The latent cooling demand varies significantly year by year due to inter-annual variability of climate change. The largest inter-annual difference is 12.27 $\mathrm{kWh} / \mathrm{m}^{2} \mathrm{y}$ for $\mathrm{CPH}$ between 2008 and 2009 , and the lowest difference is 5.62 $\mathrm{kWh} / \mathrm{m}^{2} \mathrm{y}$ for TYW between 2007 and 2009.

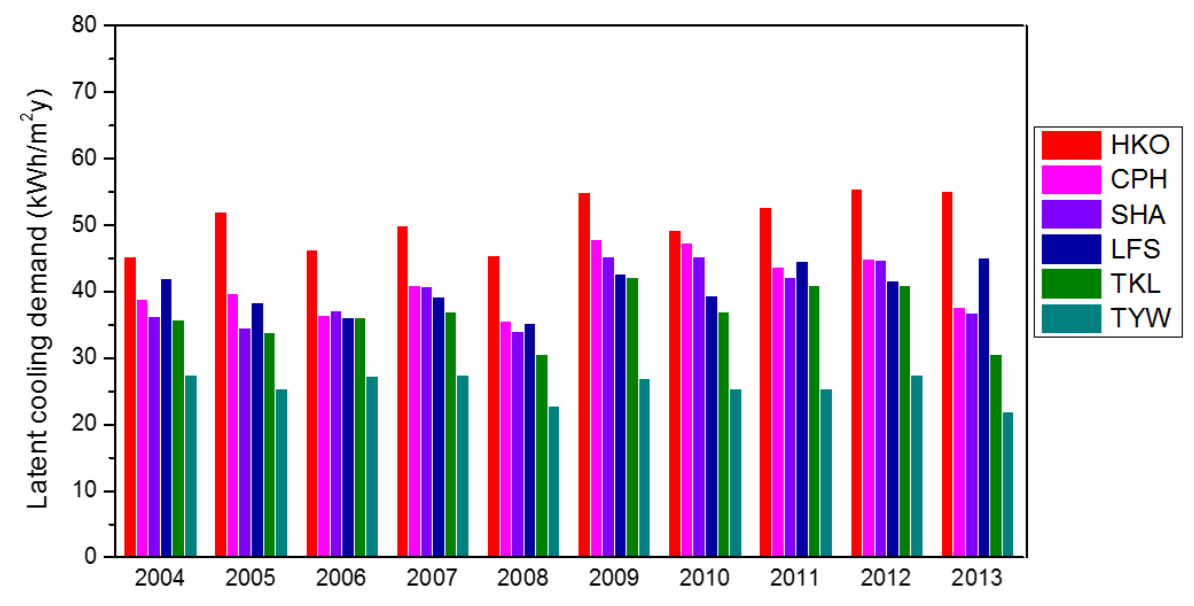

Fig.7 Simulated results for latent cooling demand of the reference residential buildings over ten years

(2004 2013) in different LCZs of Hong Kong

Similar to the results of sensible cooling demand, it is found that the latent cooling demand for dehumidification in the urban areas is always higher than rural cases in spite of the obvious inter-annual difference. This is mainly affected by the nocturnal UMII during summer in Hong Kong. Some obvious differences in the latent cooling 
demand for various LCZs are also expected. Fig.8 (a) presents the ten-tear average latent cooling energy for different LCZs during summer for a quantitative comparison. Fig.8 (b) plots the relationship between the relative difference of the dehumidification demand with UMII during summer night.

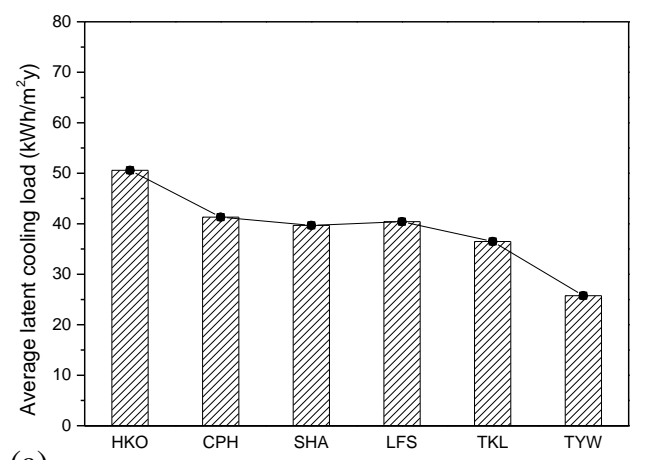

(a)

(b)

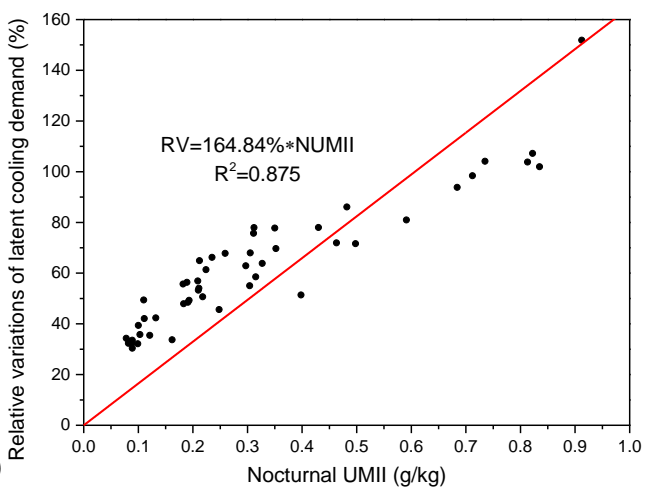

Fig.8 Average latent cooling demand at different LCZs over ten years (a) and the correlations between the relative variation (RV) of latent cooling demand and nocturnal UMII in summer (b)

On average, the dehumidification cooling demand at HKO is the largest, a total of $50.59 \mathrm{kWh} / \mathrm{m}^{2} \mathrm{y}$, which is approximately twice of the reference rural zone. CPH seconds HKO with latent cooling demand of $41.30 \mathrm{kWh} / \mathrm{m}^{2} \mathrm{y}$ and the two semi-urban zones (SHA and LFS) have almost same latent cooling energy demand as $\mathrm{CPH}$, approximately $40 \mathrm{kWh} / \mathrm{m}^{2} \mathrm{y}$. Relative low latent cooling demand are observed in two rural zones, i.e., $36.49 \mathrm{kWh} / \mathrm{m}^{2} \mathrm{y}$ for TKL and $25.76 \mathrm{kWh} / \mathrm{m}^{2} \mathrm{y}$ and TYW. As expected, the latent cooling demand for dehumidification decreases with increasing LCZ grades from the urban to the rural area. Considering TYW as the reference one, the relative variation of latent cooling demand in $\mathrm{HKO}, \mathrm{CPH}$, SHA, LFS and TKL approximately equals to $96.4 \%, 60.3 \%, 53.9 \%, 56.8 \%$, and $41.7 \%$, respectively. One interesting observation is that the latent cooling demand in LFS is a little higher than that in SHA 
possibly due to the higher UMII in LFS during summer night.

The correlation factor between the relative difference of dehumidification demand with the nocturnal UMII during summer is very high, 0.875 . This shows that relative variations of the latent cooling demand of the residential building increase linearly with UMII during summer night, and an increase of $0.1 \mathrm{~g} / \mathrm{kg}$ in UMII will lead to approximate $16.5 \%$ increase in the relative variations of the latent demand.

\subsubsection{Impact on the electricity demand}

The results for electricity demand in summer in different LCZs of Hong Kong are presented in Fig.9. It is evident that the summer electricity demand in urban buildings is always higher than that in rural buildings. On average, the electricity demand in HKO is $66.25 \mathrm{kWh} / \mathrm{m}^{2} \mathrm{y}$ and it reduces to $32.45 \mathrm{kWh} / \mathrm{m}^{2} \mathrm{y}$ in TYW significantly. This shows that the residential building in the centre of Hong Kong requires as twice as electricity amount than for the rural buildings.

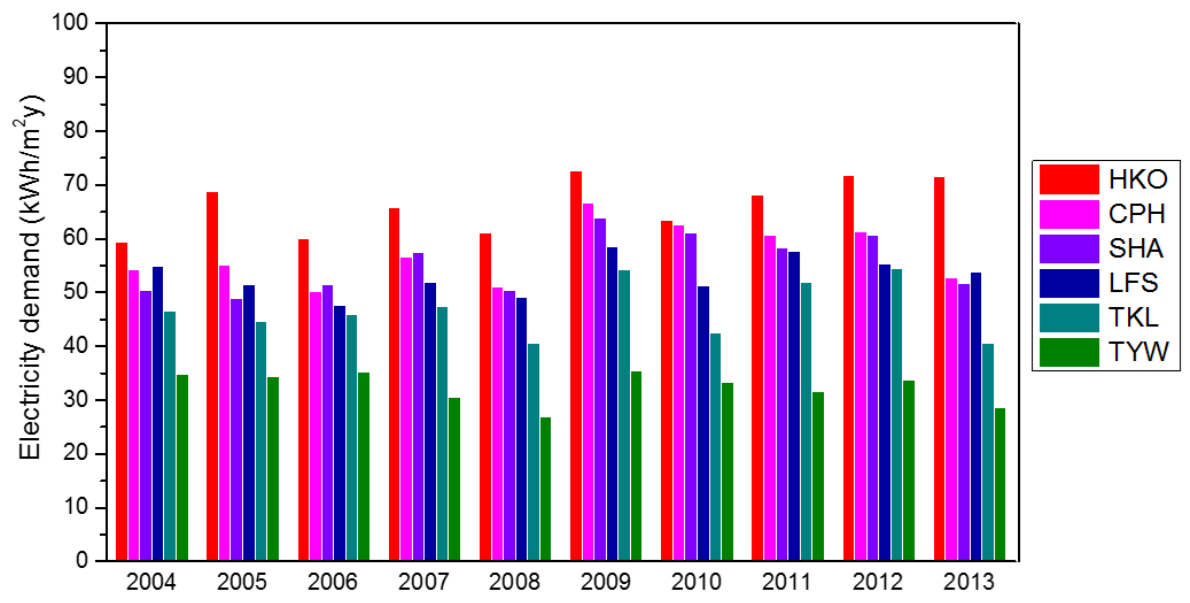

Fig.9 The electricity energy demand during summer for the reference residential buildings from 2004 to 2013 in different LCZs of Hong Kong

Additionally, the summer electricity demand shows a diminishing trend from urban 
and rural areas based on LCZs grades. HKO has the largest electricity demand over ten years. For CPH, SHA and LFS, the electricity demand has a slight reduction by an average rate of $2.0 \mathrm{kWh} / \mathrm{m}^{2} \mathrm{y}$ from $57.11 \mathrm{kWh} / \mathrm{m}^{2} \mathrm{y}$. The average summer electricity energy use in TKL is $14.44 \mathrm{kWh} / \mathrm{m}^{2} \mathrm{y}$ higher than that in TYW although TKL is located in rural area. In fact, TKL station is located only $5.0 \mathrm{~km}$ from Shenzhen and could be affected by the urban effect form Shenzhen [32].

Overall, the combination of the UHI and UMI effect leads to a significant increase in summer electricity demand concerning the residential building in Hong Kong. In addition, the cooling energy demand of various LCZs can differ to a great extent due to the spatial UHII and UMII in Hong Kong. Therefore, it is necessary to consider climate characteristics of the different local urban climate when estimating the total energy demand for the residential building in Hong Kong.

\subsection{Discussions}

It is widely acknowledged that ambient temperature is crucial to building energy consumption as it directly drives the operation of cooling and heating system and influences the corresponding building cooling and heating energy demand. The increased air temperatures in the urban areas due to UHI effect could have a negative effect on cooling-dominated buildings and mainly result in a significant increase in sensible cooling demand, especially in tropics and subtropics like Hong Kong. On the other hand, the nocturnal UMII plays an important role in shaping the vapour pressure differences, causing the moisture excess in the urban areas. The elevated urban air 
temperatures due to the high nocturnal UHI cause continued evaporation and reduced condensation in the urban areas during night. During summer night, outdoor air with high level of humidity introduced into the room could result in an increase in indoor humidity. The increased humidity in urban buildings have a negative effect on the latent cooling energy required for the fresh air dehumidification system.

The UHI studies indicates that the impact of UHI effect is generally positive for the heating load and negative for cooling load in many cities [12-14]. However, in tropical and subtropical cities, UHI effect has more impacts on cooling demand. Table 6 presents the comparative results with other cities in recent UHI studies concerning residential buildings. Specifically, the impact of UHI on summertime cooling demand varies with local climatic conditions. On the whole, with respect to the residential buildings, the cooling energy demands attributable to UHI in urban areas are between $17 \%$ and $90 \%$ for most of cities. Compared to other cities, the impact of UHI on cooling demand in Hong Kong is much more significant. The sensible cooling demand in urban building is approximately twice as much as in rural context. Indeed, the specific impact extent of UHI is also associated with the selected rural site. In this study, TYW is considered as the representative rural station, designated as Forest Zone. As LCZ grade of TYW is lower compared to previous rural site TKL (classified into Dispersed Low-Rise Zone), the difference in cooling demand between urban and rural building in Hong Kong is relatively large compared with other cities.

Concerning UMI effect, we compare the impacts of urban moisture levels on the latent cooling demand for dehumidification between Milan and Hong Kong. The 
results show completely different impacts due to the variability of urban moisture. In Milan, the urban area is drier than the rural one and this UDI effect lead to a 74 78\% reduction of latent cooling demand in urban residential building. Conversely, urban area in Hong Kong is more humid than its rural surroundings during summer nights and the latent cooling demand in urban residential buildings is $96 \%$ higher than in rural areas during summer due to UMI effect.

Table 6 The UHI impact on building cooling demand for residential buildings in some recent studies

\begin{tabular}{lll}
\hline City (year) & Impacts & Refs. \\
\hline Hong Kong, China (2019) & $45.7 \%$ 104.2\% increase in sensible cooling demand & Present study \\
Beijing, China (2018) & $17 \%$ increase in cooling energy use & {$[46]$} \\
Antwerp, Belgium (2018) & $90 \%$ increase in cooling energy demand & {$[17]$} \\
Rome, Italy (2018) & $74 \%$ increase in cooling energy consumption & {$[18]$} \\
Milan, Italy (2017) & $39 \% \sim 41 \%$ increase in cooling load & {$[21]$} \\
Barcelona, Spain (2017) & $18 \% \sim 28 \%$ increase in sensible cooling load & {$[3]$} \\
Melbourne, Australia (2014) & $8 \% \sim 11 \%$ increase in cooling energy consumption & {$[50]$} \\
Boston, USA (2013) & $5 \% \sim 41 \%$ increase in cooling energy consumption & {$[51]$} \\
Bahrain (2013) & Up to 10\% increase in cooling electricity use & {$[52]$} \\
\hline
\end{tabular}

Actually, the UHI effect is accompanied by a formation of UMI effect owing to the moisture excess in the centre of Hong Kong, and impact of urban microclimate on building cooling energy use is very complicated as it can vary significantly depending on LCZ classifications. Since different LCZs have different proportion of built, green land, and water body, UHII and UMII in different LCZs have some specific spatial characteristics in Hong Kong. Considering these findings, it is rather inaccurate to run energy simulations of buildings in various local zones using typical meteorological year as UHI and UMI effect in urban areas are not detected clearly. In terms of the residential building in Hong Kong, the cooling energy use in urban areas will be underestimated in the practice of energy assessment. 
Therefore, the UHI and UMI effect are crucial variables for the estimation of buildings energy performance in the climate of Hong Kong. While the impact of urban microclimate on building cooling use is quite complex, designers and engineers have to take into account their energy impact for the future guidelines on the design of building energy efficiency.

\section{Concluding remarks}

The focus of the present study is to investigate the spatial difference of UHI and UMI effect in Hong Kong and quantify their impact on the energy performance of residential buildings. Firstly, we analysed the average diurnal cycles of UHII and UMII for different LCZs by ten-year monitoring of air temperature and humidity in the six selected weather stations. Moreover, a calculation analysis was performed using measured weather data as input, aiming at demonstrating the impact of UHI and UMI effect on the energy demand of residential building. This study is a useful assessment of the UHII and UMII in various LCZs of Hong Kong and provides a better understanding of the variability of urban climate in this context, and we suggest that designers and engineers have to take into account their energy impacts in the estimation of building energy. The main conclusions can be drawn as follows:

(1) During summer, urban areas in Hong Kong appear as both a heat and moisture island at night, whereas at the times of sunrise they appear as a cold and dry island when compared with the rural areas.

(2) The nocturnal UHII and UMII during summer tend to both decrease with the 
increasing LCZ grades depending on the specific urban characteristics in Hong Kong. However, the daytime correlation between them is relatively low possibly due to many complicated factors.

(3) The sensible cooling demand decreases uniformly from the urban to rural areas according to the LCZ classification. An increase of $1.0^{\circ} \mathrm{C}$ in nocturnal UHII results in a $44.71 \%$ increase in relative variation of the sensible cooling demand.

(4) Similarly, latent cooling demand for dehumidification generally has a lowering tendency with increasing LCZ grades. The influences affecting differences between LCZs are attributed to the nocturnal UMII of summer nights.

(5) The combination of UHI and UMI effect could lead to a significant increase in summertime electricity demand concerning residential buildings in Hong Kong. The energy demand for various LCZs can differ to a great extent due to the spatial variability of UHII and UMII in Hong Kong.

A further study will be carried out quantitatively to investigate the formation of urban and rural humidity difference in Hong Kong by means of field measurements, including the ratio of evaporation, condensation, advection, transpiration rate of green land, and anthropogenic emissions of water vapour. The investigation could provide the better understanding of the formation of urban humidity island in Hong Kong. Besides, the conclusions of this study are merely drawn for the high-rise residential building. In the next stage, we need to study the impact of urban climate on the energy performance of typical office building in Hong Kong. 


\section{Acknowledgement}

This study was financially supported by National Natural Science Foundation of

China (No. 51878208). The first author (Shi) would like to acknowledge the financial support from Harbin Institute of Technology to conduct the research when visiting University of Reading, UK. The fourth and fifth authors (Wang and Li) acknowledges the financial support of RGC GRF grant (No 17202618).

\section{References}

[1] Levermore G, Parkinson J, Lee K, et al. The increasing trend of the urban heat island intensity[J]. Urban Climate 2018; 24: 360-8.

[2] Li H, Zhou Y, Wang X, et al. Quantifying urban heat island intensity and its physical mechanism using WRF/UCM. Science of the Total Environment 2019; 650 Part2:3110-19.

[3] Salvati A, Coch RH, Cecere C. Assessing the urban heat island and its energy impact on residential buildings in Mediterranean climate: Barcelona case study. Energy \& Buildings 2017; 146:38-54.

[4] Kim Y H, Baik J J. Maximum urban heat island intensity in Seoul [J]. Journal of Applied Meteorology 2002; 41(6):651-9.

[5] Cui Y, Yan D, Hong T, et al. Temporal and spatial characteristics of the urban heat island in Beijing and the impact on building design and energy performance. Energy 2017; 130:286-97. 
[6] Chow WTL, Roth M. Temporal dynamics of the urban heat island of Singapore. International Journal of Climatology 2006; 26(15):2243-60.

[7] Matzarakis A, Rocco M D, Najjar G. Thermal bio-climate in Strasbourg - the 2003 heat wave. Theoretical \& Applied Climatology 2009; 98(3-4):209-20.

[8] Guattari C, Evangelisti L, Balaras CA. On the assessment of urban heat island phenomenon and its effects on building energy performance: a case study of Rome (Italy). Energy \&Building 2018; 158:605-15.

[9] Sun Y, Augenbroe G. Urban heat island effect on energy application studies of office buildings. Energy \&Building2014; 77:171-9.

[10] Tian W, Song J, Li Z. Spatial regression analysis of domestic energy in urban areas. Energy 2014; 76:629-40.

[11] Li X. Linking residential electricity consumption and outdoor climate in a tropical city. Energy 2018; 157:734-43.

[12] Liu Y, Stouffs R, Tablada A, et al. Comparing micro-scale weather data to building energy consumption in Singapore. Energy \& Buildings 2017; 152: 776-91.

[13] Santamouris M. On the energy impact of urban heat island and global warming on buildings. Energy \& Buildings 2014; 82:100-13.

[14] Kolokotroni M, Ren X, Davies M, et al. London's urban heat island: Impact on current and future energy consumption in office buildings. Energy \& Buildings 2012; 47:302-11.

[15] Li X, Zhou Y, Yu S, et al. Urban heat island impacts on building energy consumption: A review of approaches and findings. Energy 2019; 174:407-19. 
[16] Palme M, Inostroza L, Villacreses G, et al. From urban climate to energy consumption. Enhancing building performance simulation by including the urban heat island effect. Energy and Buildings 2017; 145:107-20.

[17] Toparlar Y, Blocken B, Maiheu B, et al. Impact of urban microclimate on summertime building cooling demand: A parametric analysis for Antwerp, Belgium. Applied Energy 2018; 228:852-72.

[18] Zinzi M, Carnielo E, Mattoni B. On the relation between urban climate and energy performance of buildings. A three-year experience in Rome, Italy. Applied Energy 2018; 221:148-60.

[19] Fortuniak, K, Klysik, K, Wibig, J. Urban-rural contrasts of meteorological parameters in Lodz. Theoretical and Applied Climatology 2006; 84:91-101.

[20] Ryo M, Keiko W, Kazuyuki M. Urban dry island phenomenon and its impact on cloud base level. Journal of Japan Society of Civil Engineers 2013; 1:521-9.

[21] Paolini R, Zani A, Meshkinkiya M, et al. The hygrothermal performance of residential buildings at urban and rural sites: Sensible and latent energy loads and indoor environmental conditions. Energy \& Buildings 2017; 152:792-803.

[22] Deosthali V. Impact of rapid urban growth on heat and moisture islands in Pune City, India. Atmospheric Environment 2000; 34(17):2745-54.

[23] Kuttler W, Weber S, Schonnefeld J, et al. Urban/rural atmospheric water vapour pressure differences and urban moisture excess in Krefeld, Germany. International Journal of Climatology 2007; 27(14):2005-15.

[24] Richards K. Urban and rural dewfall, surface moisture, and associated 
canopy-level air temperature and humidity measurements for Vancouver, Canada. Boundary-Layer Meteorology 2005; 114(1):143-63.

[25] Giannaros TM, Melas D. Study of the urban heat island in a coastal Mediterranean City: The case study of Thessaloniki, Greece. Atmosphere Research 2012; 118(3):103-20.

[26] Wang R, Ren C, Xu Y, et al. Mapping the local climate zones of urban areas by GIS-based and WUDAPT methods: A case study of Hong Kong. Urban Climate 2018; 24:567-76.

[27] Census and Statistics Dep. of Hong Kong, 2011. http://www.census2011.gov.hk/ pdf/summary-results.pdf.

[28] Skelhorn CP, Levermore G, Lindley SJ. Impacts on cooling energy consumption due to the UHI and vegetation changes in Manchester, UK. Energy and Buildings 2016; 122:150-9.

[29] Hassid S, Santamouris M, Papanikolaou N, et al. The effect of the Athens heat island on air conditioning load. Energy \& Buildings 2000; 32(2):131-41.

[30] Lima I, Scalco V, Lamberts R. Estimating the impact of urban densification on high-rise office building cooling loads in a hot and humid climate. Energy \&Buildings $2019 ; 182: 30-44$.

[31] Yu T, Alan K, Kevin K, et al. Thermal comfort and energy performance of public rental housing under typical and near-extreme weather conditions in Hong Kong. Energy \& Buildings 2017; 156: 390-403. 
[32] Stewart I D, Oke T R. Local Climate Zones for Urban Temperature Studies. Bulletin of the American Meteorological Society 2012; 93(12):1879-900.

[33] Zheng Y, Ren C, Xu Y, et, al. GIS-based mapping of Local Climate Zone in the high-density city of Hong Kong. Urban climate 2018; 24:419-48.

[34] Siu LW, Hart MA. Quantifying urban heat island intensity in Hong Kong SAR, China. Environmental Monitoring and Assessment 2012; 185(5):4383-98.

[35] Wang W, Zhou W, Ng EYY, et al. Urban heat islands in Hong Kong: statistical modelling and trend detection. Natural Hazards 2016; 83(2):885-907.

[36] Holmer, B, Eliasson, I. Urban-rural vapour pressure differences and their role in the development of urban heat islands. International Journal of Climatology 1999; 19(9):989-1009.

[37] Liu W, You H, Dou J. Urban-rural humidity and temperature differences in the Beijing area. Theoretical and Applied Climatology 2009; 96(3-4):201-7.

[38] Yan D, Xia J, Tang W, et al. DeST d an integrated building simulation toolkit Part I: Fundamentals. Building Simulation 2008; 1(2):95-110.

[39] Shi L, Zhang H, Li Z, et al. Optimizing the thermal performance of building envelopes for energy saving in underground office buildings in various climates of China. Tunnelling \& Underground Space Technology 2018; 77:26-35.

[40] Cui Y, Yan D, Hong T, et al. Comparison of typical year and multiyear building simulations using a 55-year actual weather data set from China. Applied Energy 2017; 195:890-904.

[41] Peng C, Wang L, Zhang X. DeST-based dynamic simulation and energy 
efficiency retrofit analysis of commercial buildings in the hot summer/cold winter zone of China: A case in Nanjing. Energy \& Buildings 2014; 78:123-31.

[42] Li Z, Chen W, Deng S, et al. The characteristics of space cooling load and indoor humidity control for residences in the subtropics. Building \& Environment 2006; 41(9):1137-47.

[43] Lin Z, Deng S. A study on the characteristics of nighttime bedroom cooling load in tropics and subtropics. Building \& Environment 2004; 39(9):1101-14.

[44] Qi R, Lu L, Yang H. Impact of climate change on ventilation load and energy use of air conditioning systems in buildings of Hong Kong. International Journal of Low-Carbon Technologies 2012; 7(4):303-9.

[45] Lee WL, Chen H. Benchmarking Hong Kong and China energy codes for residential buildings. Energy \& Buildings 2008; 40(9):1628-36.

[46] Xu X, González, Jorge E, Shen S, et al. Impacts of urbanization and air pollution on building energy demand: Beijing case study. Applied Energy 2018; 225: 98-109.

[47] Chow WTL, Roth M. Temporal dynamics of the urban heat island of Singapore. International Journal of Climatology 2006; 26(15):2243-60.

[48] Oke TR. The energetic basic of the urban heat island. Quarterly Journal of the Royal Meteorological Society 1982; 108(455):1-24.

[49] Lam, Tony NT, Wan, et al. Impact of climate change on commercial sector air conditioning energy consumption in subtropical Hong Kong. Applied Energy 2010; 87(7):2321-27. 
[50] Ren Z, Wang X, Chen D, et al. Constructing weather data for building simulation considering urban heat island. Building Services Engineering Research and Technology 2014; 35(1):69-82.

[51] Street M, et al. Urban heat island in Boston- An evaluation of urban air temperature models for predicting building energy use. In: Proceedings of BS2013: 13th conference of international building performance simulation association; 2013.

[52] Radhi H, Sharples S. Quantifying the domestic electricity consumption for air conditioning due to urban heat islands in hot arid regions. Applied Energy 2013;112(0):371-80 